\title{
Faktor Resiko Keluhan Muskuloskeletal pada Penenun Tradisional Bima di Kecamatan Donggo Kabupaten Bima
}

\author{
Margareta Koreani $^{1}$, Ahmad $^{2}$, Kurniadi $^{3(\mathrm{CA})}$ \\ ${ }^{1}$ Dinas Kesehatan Kabupaten Bima, Nusa Tenggara Barat, Indonesia \\ ${ }^{2}$ Jurusan Keperawatan, Poltekkes Kemenkes Mataram, Indonesia; \\ 3(CA)Jurusan Keperawatan, Poltekkes Kemenkes Mataram, Indonesia; kurniadi.poltekkes@gmail.com \\ (Corresponding Author)
}

\begin{abstract}
There are several factors that cause musculoskeletal complaints, including occupational, environmental, psychosocial, and individual factors. One type of work with risky activities is a weaver where the weaving process is carried out in a sitting position starting from wrapping the weft threads into binoculars and linking the warp threads into the weaving comb, continuing to insert the weft threads between the warp threads by tipping using the legs alternately up and down to form a gap. then stomping the lever back and forth to tighten the weft that has been inserted. This study aims to describe the risk of musculoskeletal complaints in Bima traditional weavers using descriptive analytic method with cross sectional design. The population in this study were all Bima traditional weavers who were still active in the village of Tonggeru, Donggo District, Bima Regency, amounting to 40 people. Data collection uses the Nordic Body Map (NBM) checklist which consists of 27 assessment items. The results showed that most of the respondents had complaints of pain based on an assessment using the NBM questionnaire. For this reason, nurses should provide health education to workers regarding occupational risks and work procedures in accordance with ergonomic principles.
\end{abstract}

Keywords: musculoskeletal complaints; Bima traditional weaver

\begin{abstract}
ABSTRAK
Terdapat beberapa faktor yang menyebabkan terjadinya keluhan muskuloskeletal antara lain faktor pekerjaan, lingkungan, faktor psikososial dan individu. Salah satu jenis pekerjaan dengan aktifitas berisiko ialah penenun dimana proses menenun dilakukan dalam posisi duduk dimulai dari melilitkan benang pakan kedalam teropong dan mengaitkan benang lungsi kedalam sisir tenun, dilanutkan memasukan benang pakan diantara benang lungsi dengan menjungkit menggunakan kaki bergantian naik dan turun agar terbentuk celah, kemudian menghentakan kayu pengungkit maju dan mundur untuk merapatkan benang pakan yang sudah dimasukan. Penelitian ini bertujuan untuk mengetahui gambaran resiko keluhan muskuloskeletal pada penenun tradisional Bima menggunakan metode deskriptif analitik dengan rancangan cross sectional. Populasi pada penelitian ini ialah semua penenun tradisional Bima yang masih aktif di Desa Tolonggeru Kecamatan Donggo Kabupaten Bima yang berjumlah 40 orang. Pengumpulan data menggunakan checklist Nordic Body Map (NBM) yang terdiri dari 27 item penilaian. Hasil penelitian menunjukan sebagian besar responden memiliki keluhan sakit berdasarkan penilaian menggunakan kuesioner NBM. Untuk itu perawat sebaiknya memberikan pendidikan kesehatan pada pekerja mengenai risiko pekerjaan dan tata cara bekerja yang sesuai dengan prinsip ergonomi.
\end{abstract}

Kata Kunci : keluhan musculoskeletal; penenun tradisional bima 


\section{PENDAHULUAN}

Tubuh manusia dirancang untuk bisa melakukan segala aktivitas dalam pekerjaan seharihari.Massa otot dalam tubuh bobotnya hampir lebih dari separuh dari berat tubuh, yang memungkinkan manusia biasmelakukan suatu pekerjaan dimana pekerjaan merupakan suatu hal yang penting dalam kehidupan manusia.Melalui pekerjaan tersebut manusia akan dapat membuka wawasannya dan dapat bersosialisasi dengan keadaan dan orang-orang di sekitarnya. Dalam melakukan suatu pekerjaan tidak terlepas dari sebuah resiko yang ditimbulkan, salah satunya adalah keluhan muskuloskeletal atau musculoskeletal disorders (Tarwaka, 2015).

Keluhan muskuloskeletal merupakan keluhan yang dirasakan pada otot skeletal dari keluhan yang ringan sampai parah.Studi tentang keluhan muskuloskeletal pada berbagai jenis aktivitas kerja menunjukkan bahwa keluhan otot yang sering dirasakan antara lain pada otot leher, bahu, lengan, tangan, jari, punggung, pinggang, dan otot-otot bagian bawah (Tarwaka, 2015)

Bureau of Labour Statistics (BLS) di Amerika melaporkan bahwa pada tahun 2007 terdapat sebanyak 29 gangguan muskuloskeletal dari semua cedera akibat kerja (BLS,2008). International Labour Organization (ILO) pada tahun 2013 dalam program The prevention of occupational disease menyebutkan bahwa musculoskeletal diseases (MSDs) termasuk carpal tunnel syndrome mewakili 59\% dari keseluruhan catatan penyakit yang ditemkan pada tahun 2005 di Eropa. Di Korea, keluhan muskuloskeletal mengalami peningkatan yang sangat tinggi dari 1.634 pada tahun 2001 menjadi 5.502 pada tahun 2010 (ILO, 2013).

Sementara itu di Indonesia penelitian yang dilakukan doleh Nurliah (2012), pada peneleitiannya terkait Analisa Resiko Musculoskeletal Disorders ( MSDs) pada operator forklift yang menjadi responden $87 \%$ mengalami MSDs, titik keluhan yang dirasakan antara lain pinggang (65\%), leher atas (60\%), leher bawah $(60 \%)$ punggung $(48 \%)$ dan bahu kanan (45\%) .Penelitian juga yang dilakukan Riyadina dkk (2008) yang melibatkan 800 orangdari 8 sektor informal di tanah air menunjukkan hasil bahwa keluhanmuskuloskeletal dialami oleh 31,6 \% petani kelapa sawit di Riau, 21\% perajinwayang kulit di Yogyakarta, 18\% perajin Onyx di Jawa Barat, 16,4\% penambang emas di Kalimantan Barat, 14,9\% perajin sepatu di Bogor, dan8\% perajin kuningan di Jawa Tengah. Perajin batu bata diLampung dannelayan di DKI Jakarta adalah kelompok pekerja yang paling banyakmenderita gangguan muskuloskeletal, masing $76,7 \%$ dan $41,6 \%$.

Terdapat beberapa faktor yang menyebabkan terjadinya keluhan muskuloskeletal antara lain faktor pekerjaan, lingkungan, faktor psikososial dan individu. Penyebab pekerjaan yaitu peregangan otot berlebihan, aktivitas berulang, atau sikap kerja tidak alamiah. Penyebab lingkungan yaitu, tekanan, getaran, dan mikroklimat. Penyebab kombinasi dan faktor individu seperti usia, jenis kelamin, kebiasaan merokok, aktivitas fisik, kekuatan fisik dan ukuran tubuh sangat berperan dalam hal terjainya keluhan musculoskeletal (Tawarka, 2015).

Masyarakat Tolonggeru memiliki berbagai jenis pekerjaanseperti PNS, buruh, honorer, TNI/Polri, sopir, tukang kayu, bidan, perawat, penenun dan petani. Salah satu jenis pekerjaan dengan aktifitas berisiko ialah penenun dimana proses menenun dilakukan dalam posisi duduk dimulai dari 
melilitkan benang pakan kedalam teropong dan mengaitkan benang lungsi kedalam sisir tenun, dilanutkan memasukan benang pakan diantara benang lungsi dengan menjungkit menggunakan kaki bergantian naik dan turun agar terbentuk celah, kemudian menghentakan kayu pengungkit maju dan mundur untuk merapatkan benang pakan yang sudah dimasukan (Enie,1980 dalam Sari, 2014).

Penelitian yang dilakukan Koesyanto (2013) pada penenun sarung didesa wana reja utara pemalang diperoleh hasil terdapat hubungan antara usia, sikap kerja duduk dan masa kerja dengan nyeri punggung. Hasil penelitan Butar-butar (2018) pada pekerja tenun ulos terdapat pengaruh antara masa kerja dan lama kerja dengan musculoskeletal disorder (MSDs). Penelitian ini bertujuan untuk mengetahui gambaran resiko keluhan muskuloskeletal pada penenun tradisional Bima di Tolonggeru desa Mbawa, kecamatan Donggo, kabupaten Bima.

\section{METODE}

Sesuai dengan tujuan yang ingin dicapai, penelitian menggunakan metode deskriptif analitik dengan rancangan cross sectional. Populasi pada penelitian ini ialah semua penenun tradisional bima yang masih aktif di Desa Tolonggeru Kecamatan Donggo Kabupaten Bima yang berjumlah 40 orang. Pengumpulan data menggunakan checklist Nordic Body Map (NBM) yang terdiri dari 27 item penilaian untuk mengetahui keluhan musculoskeletal disorders dan meteran untuk mengukur jarak pandang dan tinggi tempat duduk penenun. Keluhan musculoskeletal dibagi menjadi 3 kategori berdasarkan klasifikasi kuesioner NBM. Keluhan musculoskeletal dikatakan "tidak sakit" jika total nilai yang diperoleh antara 0 - 9 poin pada jawaban kuesioner, "agak sakit" jika total nilai yang diperoleh antara $10-18$ dan sakit bila nilai antaran $19-27$.

Analisis data hasil penelitian menggunakan tabel distribusi frekuensi dan persentase. Selama pelaksanaan penelitian/pengumpulan data peneliti selalu memperhatikan aspek etika seperti keterlibatan responden yang bersifat sukarela dan sewaktu-waktu dapat mengundurkan diri tanpa adanya sanksi apapun, semua informasi dan hasil pemeriksaan yang berkaitan dengan responden dijaga kerahasiaannya serta penyajian data tidak akan dihubungkan dengan identitas responden.

\section{HASIL}

Pada penyajian data ini akan mendeskripsikan gambaran faktor risiko kelurahan musculoskeletal meliputi deskripsi lokasi penelitian, distribusi responden berdasarkan umur, masa kerja, sandaran punggung, jarak pandang, durasi kerja, bantalan duduk dan keluhan musculoskeletal.

Tabel 1. Karakteristik responden berdasarkan umur, lama menjadi penenun dan durasi kerja

\begin{tabular}{clcc}
\hline No & Karakteristik responden & Jumlah $(\mathrm{n}=40)$ & Persentase $(\%)$ \\
\hline 1 & Kelompok umur & & \\
& $17-25$ tahun & 2 & 5,0 \\
& $26-35$ tahun & 6 & 15,0 \\
& $36-45$ tahun & 21 & 52,5 \\
& $46-65$ tahun & 11 & 27,5 \\
\hline
\end{tabular}




\begin{tabular}{llcc}
\hline No & Karakteristik responden & Jumlah $(\mathrm{n}=40)$ & Persentase $(\%)$ \\
\hline 2 & Lama menjadi penenun & & \\
& < 5 Tahun & 12 & 30,0 \\
& 6 - 9 Tahun & 4 & 10,0 \\
& $>$ 10 Tahun & 24 & 60,0 \\
3 & Durasi Kerja & & \\
& Normal (<8 Jam /hari) & 30 & 75,0 \\
& Tidak normal (> 8 jam/hari) & 10 & 25,0 \\
\hline
\end{tabular}

Dari tabel 1 diketahui bahwa umur responden sebagian besar berada pada kelompok usia 36 - 45 tahun dengan lama menjadi penenun > 10 tahun, serta durasi kerja setiap hari kurang dari 8 jam.

Tabel 2. Karakteristik responden berdasarkan alat tenun yang digunakan

\begin{tabular}{llcc}
\hline No & Karakteristik alat tenun & Jumlah $(\mathrm{n}=40)$ & Persentase $(\%)$ \\
\hline 1 & Sandaran punggung & 16 & \\
& Ada & 24 & 40,0 \\
& Tidak ada & & 60,0 \\
2 & Bantalan duduk & 25 & 62,0 \\
& Ada & 15 & 38,0 \\
& Tidak ada & & \\
3 & Jarak pandang & 21 & 52.5 \\
& Sesuai $(20-30 \mathrm{~cm})$ & 19 & 47,5 \\
& Tidak sesuai $(<20 \mathrm{~cm}$ atau $>30 \mathrm{~cm})$ & &
\end{tabular}

Berdasarkan tabel 2 diketahui alat tenun yang digunakan sebagian besar tidak memiliki sandaran punggung, ada bantalan duduk dengan jarak pandang $20-30 \mathrm{~cm}$.

Tabel 3. Keluhan Muskuloskeletal Pada Penenun Tradisional Bima

\begin{tabular}{lcc}
\hline Keluhan muskuloskeletal & Jumlah $(\mathrm{n}=40)$ & Persentase $(\%)$ \\
\hline Tidak Sakit & 4 & 10,0 \\
Agak Sakit & 17 & 42,5 \\
Sakit & 19 & 47,5 \\
\hline
\end{tabular}

Berdasarkan tabel 3 diketahui bahwa sebagian besar responden memiliki keluhan sakit berdasarkan penilaian menggunakan kuesioner NBM. 


\section{PEMBAHASAN}

Proses penelitian berawal dari pengurusan izin beberapa pihak terkait, izin penelitian dari pihak Akademik dan Kantor Desa Mbawa Kecamatan Donggo Kabupaten Bima. Setelah mengidentifikasi jumlah penenun tradisional di Desa Tolonggeru Kecamatan Donggo Kabupaten Bima, peneliti menjelaskan maksud dan tujuan penelitian kepada para penenun tersebut, jika bersedia untuk dijadikan responden. Setelah klien/responden mengerti peneliti melakukan kontrak dengan penenun tersebut untuk bersedia menjadi responden penelitian. Sesuai dengan tujuan khusus pada BAB I, maka poin yang akan dibahas pada hasil penelitian ini yaitu untuk mengidentifikasi karakteristik responden dan keluhan musculoskeletal pada penenun tradisional di Desa Tolonggeru Kecamatan Donggo Kabupaten Bima.

Keluhan musculoskeletal adalah keluhan pada bagian-bagian otot skeletal yang dirasakan oleh seseorang mulai dari keluhan sangat ringan sampai sangat sakit. Berdasarkan observasi yang telah dilakukan, umur responden berkisar antara umur 21 sampai 80 tahun. Rata-rata umur responden penenun adalah 36 - 45 tahun sedangkan rata-rata masa kerja responden adalah lebih dari 10 tahun. Umumnya keluhan otot skeletal mulai dirasakan pada usia kerja yaitu 25-65 tahun. Pada umur 35 tahun sebagian besar pekerja mengalami peristiwa pertama dalam sakit punggung dan tingkat kelelahan akan terus bertambah sesuai dengan bertambahnya umur dikarenakan pada umur setengah baya, kekuatan dan ketahanan otot mulai menurun sehingga risiko terjadinya keluhan otot meningkat.

Hasil penelitian ini diperkuat oleh hasil penelitian Asni Sang (2013) yang menunjukkan hasil uji statistik menggunakan uji statistic memperoleh nilai $(\mathrm{p}=0,044)$ sehingga dinyatakan terdapat hubungan yang bermakna antara umur dengan keluhan Musculoskeletal Disorders Pada Pemanen Kelapa Sawit PT Sinergi Perkebunan Nusantara Tahun 2013. Upaya yang dilakukan untuk dapat menghindari timbulnya Musculoskeletal Disorders (MSDs) yaitu dengan melakukan istirahat yang cukup bagi pekerja yang berusia $\geq 35$ tahun agar tidak terlalu berisiko menimbulkan keluhan Musculoskeletal Disorders.

Berdasarkan hasil observasi yang telah dilakukan, didapatkan hasil bahwa sebagian besar penenun mengalami keluhan musculoskeletal dengan kategori sakit sebanyak 47,5\%, kategori agak sakit sebanyak 42,5\% dan tidak sakit sebanyak 10\%. Menurut Oborne (2014), keluhan otot skeletal biasanya dialami seseorang pada usia kerja yaitu 24-65 tahun dan tingkat keluhan akan meningkat seiring dengan bertambahnya usia. Cohen et al (2010) mengungkapkan bahwa gangguan penyakit atau cidera pada sistem musculoskeletal disorders hampir tidak pernah terjadi secara langsung akan tetapi lebih merupakan suatu akumulasi dari benturan kecil maupun besar secara terus-menerus dan dalam jangka waktu yang relative lama.

Masa kerja mempengaruhi keluhan musculoskeletal pada penenun di Desa Tolonggeru Kecamatan Donggo. Hasil ini juga dipengaruhi bahwa semakin lama masa kerja seseorang maka semakin lama pula keterpaparan terhadap waktu dan jenis pekerjaan yang dilakukan oleh pekerja, sehingga akan menimbulkan keluhan keluhan fisik akibat pekerjaannya sendiri. Hasil penelitian ini sejalan dengan penelitian yang dilakukan oleh Masliah (2014) mengenai Faktor Yang Berhubungan Dengan Keluhan Musculoskeletal Disorders (MSDs) Pada Pekerja Manual Handling Di Pelabuhan Makassar Diketahui hasil uji chi square diperoleh $(\mathrm{p}=0,004)$ untuk variabel masa kerja terhadap keluhan Musculoskeletal 
Disorders (MSDs). Dengan demikian bahwa ada hubungan yang bermakna antara masa kerja dengan keluhan Musculoskeletal Disorders. Pada jenis pekerjaan apapun, masa kerja sangat berhubungan dengan tingkat keterpaparan tenaga kerja terhadap lingkungan kerjanya. Semakin lama orang bekerja dengan aktivitasnya, maka risiko terjadinya keluhan MSDs semakin besar pula.

Keberadaan sandaran punggung mempengaruhi keluhan musculoskeletal pada penenun di Desa Tolonggeru Kecamatan Donggo Kabupaten Bima. Berdasarkan wawancara dengan responden yang tidak menggunakan sandaran punggung pada proses penenun dalam tahapan menenun, mereka kebanyakan mengeluh sakit nyeri otot pada bagian leher bagian bawah, lengan atas kiri, punggung, lutut. Hal ini dilihat dari sikap kerja saat melakukan pekerjaan yaitu dengan sikap kerja duduk tegang/kaku dan terkadang tubuh sedikit miring dan cenderung membungkuk. Sikap duduk yang seperti itu merupakan penyebab adanya keluhan pada leher, punggung, pinggang dan bokong karena tekanan pada tulang belakang akan meningkat pada saat duduk dibandingkan dengan saat berdiri ataupun berbaring. Jika diasumsikan tekanan tersebut sekitar 100\%; maka cara duduk yang tegang atau kaku (erect posture) dapat menyebabkan tekanan tersebut mencapai $140 \%$ dan cara duduk yang dilakukan dengan membungkuk ke depan menyebabkan tekanan tersebut sampai 190\% (Nurmianto, 2004)

Pada penenun yang tidak menggunakan sandaran punggung, kebanyakan mengeluh sakit nyeri otot pada bagian leher bagian bawah, lengan atas kiri, punggung, dan lutut. Posisi tubuh penenun tulis pada saat menenun dimana terdapat posisi yang memiliki risiko cidera. Bagian tubuh yang paling banyak dirasakan pegal atau nyeri sehingga perlu adanya perbaikan pada kursi seperti memberikan sandaran agar penenun dapat menjaga tubuh tetap tegak dan mengurangi keluhan yang ada.

Berdasarkan observasi yang dilakukan pada responden dengan durasi kerja yang tidak normal (>8 jam/hari) kebanyakan mengeluh sakit nyeri otot pada bagian leher, bahu, punggung, pantat, pergelangan tangan, tangan, paha, lutut, pergelangan kaki dan kaki. Berdasarkan wawancara dengan penenun, kebanyakan penenun mulai bekerja pada pukul 08.00-16.00. Responden dengan durasi kerja $\leq 8$ jam atau lebih dari 8 jam bukan berarti selama itu penenun terus menerus bekerja. Ada beberapa jeda untuk istirahat dan juga tergantung dengan kepentingan penenun, jika ada acara di masyarakat mereka mengikuti acara tersebut dan tidak menenun.

Hasil penelitian ini sejalan dengan penelitian yang dilakukan oleh Utami (2017) mengenai Hubungan Lama Kerja, Sikap Kerja Dan Beban Kerja Dengan Muskuloskeletal Disorders (MSDs) Pada Petani Padi Di Desa Ahuhu Kecamatan Meluhu Kabupaten Konawe Tahun 2017. Hasil penelitian dari 62 responden, sebagian besar responden berada pada waktu pekerja yang tidak normal sebanyak 42 orang $(67,7 \%)$ sedangkan sisa responden berada pada waktu pekerja yang normal sebanyak 20 orang $(32,3 \%)$. Diketahui hasil uji chi square diperoleh $(\rho=0,005)$ untuk variabel lama kerja terhadap keluhan Musculoskeletal Disorders (MSDs). Dengan demikian bahwa ada hubungan yang bermakna antara lama kerja dengan keluhan Musculoskeletal Disorders. Hasil observasi ini sejalan dengan penelitian Utami (2017) yang menyatakan bahwa terdapat hubungan yang bermakna antara lama kerja/durasi kerja dengan musculoskeletal pada petani padi di Desa Ahuhu tahun 2017.

Jika pekerjaan berlangsung dalam waktu yang lama tanpa istirahat, kemampuan tubuh akan menurun dan dapat menyebabkan kesakitan pada anggota tubuh. Pada pekerja yang bekerja 41 - 48 
jam/minggu atau rata- rata 7- 8 jam perhari menyebabkan waktu istirahat yang berkurang dan kerja otot lebih berat sehingga risiko kejadian nyeri punggung akan meningkat. Hal ini juga sesuai dengan hasil penelitian risiko terjadinya musculoskeletal pada pekerja yang mempunyai lama kerja > 8 jam 1.552 kali lebih besar dibandingkanpekerja dengan lama kerja < 8 jam (Alamsyah dan Ratna, 2013).

\section{KESIMPULAN}

Keluhan musculoskeletal pada penenun tradisional bima di Desa Tolonggeru Kecamatan Donggo Kabupaten Bima didapatkan hasil dari 40 responden yang diteliti, bahwa yang paling banyak adalah responden yang dengan mengeluh sakit. Keluhan ini dipengaruhi oleh keberadaan sandaran punggung, jarak pandang, durasi kerja, serta keberadaan bantalan duduk. Oleh karena itu dalam pelayanan keperawatan sebaiknya memberikan penyuluhan, pelatihan atau training pada pekerja mengenai risiko pekerjaan dan tata cara bekerja yang sesuai dengan prinsip ergonomi untuk menciptakan sistem kerja yang aman, nyaman, dan tetap sehat bagi pekerja saat bekerja.

\section{DAFTAR PUSTAKA}

Affendi.(1995). The Challenge of Modernity: The Quest for Authenticity in the Arab Word Louay M.Safi.Lanham,MD: University Press of America,1994,pp.211.American journal of islam and Society, 1995,12.1:111-114.

Afianto, I.D. Utami, H. N. 2017.'Pengaruh Disiplin Kerja dan Komunikasi Organisasi Terhadap Kepuasan Kerja dan Kinerja Karyawan (Studi pada Karyawan Divisi Marketing PT. Victory International Futures Kota Malang)', Administrasi Bisnis, 50(6), pp. 58-67.

Akobunduet al.2008. Physical Characteristics And Acceptability Of Extrudet African Breadfruit Based Snack. Journal of food quality, 31(2), 142-155.

Asni Sang RD, Syamsiar S. Russeng. 2013. Hubungan Risiko Postur Kerja Dengan Keluhan Musculoskeltal Disorders (MSDs) Pada Pemanen Kelapa Sawit Di PT. Sinergi Perkebunan Nusantara.

Butar-Butar, (2018).Does Auditor Industry Expertise Improve Audit Quality In Complex Business Environments?. Jurnal Akuntansi dan Keuangan, 20(1), 1-12.

CCOHS. 2014.Canadian Centre for Occupational Health and Safety (2014). Basic information on Standing at work.

Cindyastira, 2014. Hubungan Intensitas Getaran Dengan Keluhan Muskuloskeletal Disorders (MSDs) Pada Tenaga Kerja Unit Produksi Paving Block CV. Sumber Galian Makassar Univ Hasanuddin.

Cohen, Alexander dkk (2010). Elemen Program Egronomic. Evaluasi Tempat Kerja Primer Basedon dari Gangguan Muskuloskeletal. AS : Departmenof Health and Human Service NIOSH.

Corlett, 1992. An anatomic review of the delay phenomenon: II.Clinical applications. Plastic and reconstructive surgery, 89(3), 408-16.

Daryono, 2016. Redesain Rakel dan Pemberian Peregangan Aktif Menurunkan Beban Kerja dan Keluhan Muskuloskeletal Serta Meningkatkan Produktivitas Kerja Pekerja Sablon Pada Industri Sablon Surya Bali di Denpasar. Jurnal Ergonomi Indonesia, 2(2), 15-26. 
Deyyas, and Tafese,2014. Environmental and organizational factors associated with elbow/forearm and hand/wrist disorder among sewing machine operators of garment industry in Ethiopia. Journal of environmental and public health, 2014.

Elyas,2012. Teaching and moral tradition in Saudi Arabia: a paradigm of struggle or pathway towards globalization?. Procedia-Social and Behavioral

Grandjean. 1993. Simultaneous deposition of Pd and Ag on porous stainless steel by electroless plating. Journal of Membrane Science, 77(2-3), 181-195.Sciences, 47, 1083-1086.

Handayani, 2011. Faktor-Faktor Yang Berhubungan Dengan Keluhan Musculoskeletal Disorders Pada Pekerja Di Bagian Polishing Pt. SuryaToto Indonesia. Tbk Tangerang, Skripsi Program studi Kesehatan Masyarakat Fakultas Kedokteran Dan Ilmu Kesehatan Universitas Islam Negeri Syarif Hidayatullah Jakarta.

Koesyanto. 2013. Masa Kerja dan Sikap Kerja Duduk Terhadap Nyeri Punggung.Jurnal Kesehatan Masyarakat.

Maijunidah E, 2010. Faktor-Faktor yang Mempengaruhi Keluhan Musculoskeletal Disorders (MSDs) pada Pekerja Assembling PT X Bogor [Skripsi].Jakarta:

Masliah, dkk. 2014. Faktor yang Berhubungan Dengan keluahan Musculoskeletal Disoeders (MDS) Pada Pekerja Manual Handling di Pelabuhan Makkasa. Depertamen K3 UNHAS.

NIOSH.1997. Musculoskeletal Disorders and Workplace Faktors:A Critical Reviewof Epidemiologic Evidence for Work Related MusculoskeletalDisoeder.NIOSH: Centers of Disease Contrrol and Prenvention.

Nur,Hikmah. 2011. Faktor-faktor yang Berhubungan Dengan Muskuloskeletal Disorders (MSDs) pada pekerja Furniture di Kecamatan Benda Kota Tangerang Tahun 2011. Skripsi.UIN Syarif Hidayatullah.

Nurliah, Aah. "Analisis Risiko Muscoloskeletal Disorders (MSDs) Pada Operator Forklift di PT LLI."Universitas Indonesia (2012).

Oborne, David J. 2014. Ergonomic at Work, Human Factor in Design Ana Development. 3rd Edition. John Wiley and Sons ltd : Chicester

Payuk, 2013. Hubungan Faktor Ergonomis Dengan Beban Kerja Pada Petani Padi Tradisional Di Desa Congko Kecamatan Marioriwawo Kabupaten Soppeng.Bagian Kesehatan Dan Keselamatan Kerja Fakultas Kesehatan Masyarakat Universitas Hassanudin Makassar.Makassar.

Riyadina,et al.2008. Cedera Akibat Kerja Pada Pekerja industri di kawasan industri pulo Gadung Jakarta.Jurnal Kedokteran,2008

Sari. 2014. Tenun Ikat ATBM di Home Industry Kurniawan Bandar

Soedarjatmi, 2003. Hubungan Antara Pola Kerja Dengan Nyeri Punggung Bawah Pada Perawat Rsu Tugurejo Semarang (Doctoral dissertation, Diponegoro University).

Sutajaya,1998.Perbaikan Kondisi Kerja Mengurangi Gangguan Terhadap Muskuloskeletal dan Denyut Nadi Kerja Serta Meningkatkan Produktivitas Pematung di Desa Pelihatan Ubud, Kabupaten Gianyar (Doctoral dissertation, Tesis).

Suwati, Kartiwa. 1973. Kain Tenun Tradisional Nusa Tenggara. Jakarta: MuseumPusat Jakarta 